\title{
El Theophrastus redivivus Religión y poder político a mediados del siglo XVII
}

Carlos Daniel Lasa* María de los Ángeles Lasa **

\begin{abstract}
Resumen
El presente escrito da cuenta de la posición asumida por un autor anónimo, en el célebre Theophrastus redivivus (1659), respecto de la relación entre religión y poder político. Para el autor del Theophrastus, la religión ha sido inventada por los legisladores con el propósito de configurar la polis. La antropología negativa asumida por el autor del Theophrastus, por lo tanto, lo conduce a afirmar que el vulgo, movido solo por pasiones, es incapaz de vivir conforme a la razón y la verdad (es decir, conforme al ateísmo). De este modo, la sociedad siempre se sostiene en una escisión profunda entre los sabios y los ignorantes. La vida política dependerá, entonces, de la interacción constante entre estos dos tipos de hombres y su fortaleza será proporcional a la subordinación de la masa a la élite. El es-
\end{abstract}

* Investigador independiente de CONICET, profesor en la Universidad Nacional de Villa María, Universidad Católica de Córdoba, y Universidad Católica de Salta.

** Asistente de Investigación en el Laboratorio de Microgeopolítica de la Facultad de Ciencias Sociales de la Universidad de Buenos Aires.

Código de Referato: SP.215.XLI/17

http://dx.doi.org/10.22529/sp.2017.41.05

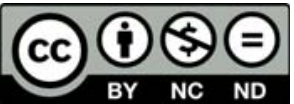

STUDIA POLITICAE sg Número 41 otoño 2017

Publicada por la Facultad de Ciencia Política y Relaciones Internacionales, de la Universidad Católica de Córdoba, Córdoba, República Argentina. 
fuerzo de la élite será el de mantener siempre esta relación jerárquica y para ello, como ya quedó dicho, la religión resulta indispensable.

Palabras Clave: Siglo XVII - Theophrastus - Religión - Política

\begin{abstract}
This paper focuses on the position taken by an anonymous author, in the well-known writing Theophrastus Redivivus (1659), on the relationship between religion and political power. For the unknown author, lawmakers have invented religion in order to organize cities. The negative anthropology assumed by the author of Theophrastus leads him to affirm that common people, moved only by passions, are unable to live according to reason and truth (i.e. atheism). A rift between the wise and the ignorant, thus, always traverses societies. In this sense, political coexistence is the consequence of a constant interaction between these two types of men, and its strength will depend on the subordination of the masses to the elite. The efforts by the elite, therefore, will be oriented toward the maintenance of this hierarchical relationship, and for this — as aforementioned — religion is key.
\end{abstract}

Keywords: $17^{\text {th }}$ Century - Theophrastus - Religion - Politics

\title{
1. El escrito
}

$\mathrm{D}$ ECLINANDo el siglo XVI, se observa un marcado escepticismo respecto de aquellos principios que habían regido la concepción política y que estaban fundados en una metafísica cristiana. La destacada estudiosa italiana, Ana Maria Battista, lo refiere en estos términos:

Hacia fines del siglo XVI se manifiesta en Francia un interesante fenómeno de reacción a la dirección política prevalente, todavía heredera... de los ejes conceptuales definidos por Aristóteles y reelaborados por la filosofía política cristiana. Más que una veta definida de pensamiento, resulta oportuno hablar de una actitud psicológica y mental que refleja aquella decadencia de los valores políticos y civiles, íntimamente unida a los trágicos acontecimientos vividos por Francia en la segunda mitad del siglo XVI (Battista, 1966, p. 2).

La decadencia de los valores políticos y civiles tiene como correlato un cuestionamiento radical de la visión metafísico-cristiana que orientaba la vida de los hombres. Esta discusión está presente tanto en el pensamiento de Giulio Cesare Vanini (1585-1619) como en el de los libertinos.

Poco después de mediados del siglo XVII, más concretamente en el año 1659, un autor anónimo publica una obra titulada Theophrastus redivivus. 
Una copia de este manuscrito se encuentra en la Bibliothèque Nationale de París, otro ejemplar ha sido conservado en la Nationalbibliothek de Viena y un tercero estuvo en posesión de Georg Wilhelm, barón de Hohendorf. Esta obra, junto a toda la biblioteca del barón, pasó a la Biblioteca Palatina de Viena en 1720 y actualmente se encuentra en la Nationalbibliothek. A estos tres manuscritos se añade el de Lennik (Bélgica), Collection Prof. Dr. Jeroom Vercruysse (Canziani/Paganini, 1981, p. LXXIII).

La única edición crítica existente del manuscrito latino Theophrastus redivivus fue realizada por Guido Canziani y Gianni Paganini. La misma se basa en la copia del manuscrito W (Wien), cod. 11.451 (Rec. 452) de la Nationalbibliothek de Viena que tiene setecientas páginas numeradas.

Esta edición crítica, señala el destacado erudito italiano Bianchi, se impone de inmediato a la atención de los estudiosos por dos motivos: en primer lugar, porque permite disponer de un texto seguramente central en la cultura libertina y erudita del siglo XVII pero cuyo significado ha sido, en general, o infravalorado o mal comprendido debido al escaso o incompleto conocimiento de la misma obra; en segundo lugar, porque un contacto directo con el escrito permite que se desarrollen estudios reconstructivos y más ponderados (Bianchi, 1988, p. 109).

La existencia de este manuscrito era poco conocida, por lo menos hasta el primer tercio del siglo XX. Ira O. Wade había señalado las numerosas referencias al Theophrastus redivivus en la literatura clandestina del siglo XVIII, pero consideraba que la obra se había perdido (Wade, 1938, pp. 222-228). Fue J. S. Spink quien encontró el manuscrito (fonds latin 9324), de mil noventa páginas, en la Biblioteca Nacional de París (Spink, 1937, 248-255). Sostenía Spink que este voluminoso compendio ya contenía las principales ideas y opiniones de toda la izquierda del movimiento filosófico y constituía una vasta cantera de propaganda antirreligiosa de la cual los autores no creyentes podían extraer elementos a voluntad.

Henri Busson, habla del Theophrastus redivivus como de un libro "viejo desde su mismo nacimiento" (Busson, 1948, p. 186-187) y considera que su autor permaneció ajeno a la filosofía cultivada en su tiempo. René Pintard, en su destacada obra sobre el libertinismo erudito, señala que el Theophrastus da cuenta de un pensamiento situado "fuera de su tiempo", que extrae sus ideas de viejos libros. Y añade Pintard que esta obra ha sido la más impía que se haya compuesto en su tiempo (Pintard, 1983, pp. 433 y 568).

Una valoración del todo diversa a las que hemos referido precedentemente formula Eugenio Garin. Para Garin, en el Theophrastus redivivus se opera la unión entre la tradición del renacimiento italiano y la ciencia y filosofía de los modernos, es decir, entre Pomponazzi, Cardano, Bruno y Campane- 
lla, por un lado, y Galileo, Descartes y Gassendi, por el otro. Y añade Garin: "Y todo bajo la protección de las grandes sombras de Demócrito y Lucrecio resucitados, y de Platón y Epicuro santificados: éste es, precisamente, el fondo europeo sobre el cual se puede delinear una no escasa parte del pensamiento pre-viquiano en Italia” (Garin, 1970, 245).

Para Tullio Gregory, el Theophrastus se caracteriza por su sistematicidad y claridad (Gregory, 1979, p. 11) y advierte que la utilización de toda la tradición filosófica antigua no se hace en vistas de encontrar en la misma los presupuestos y el sostén filosófico de la tradición espiritualista cristiana, sino los fundamentos de aquella filosofía libre, impía y ateísta que el pensamiento libertino venía proponiendo con extrema cautela y sutiles simulaciones.

El siglo XVII, a juicio de Gregory, condujo a la consumación y a la transformación de horizontes culturales, no solo porque fue capaz de delinear nuevos mundos físicos y metafísicos, sino porque, incluso a través de una nueva utilización de lo antiguo, alcanzó a liberar la cultura de seculares tabúes y a ordenar dentro de límites y orígenes humanos escalas de valores consideradas intangibles (Gregory, 1979, p. 12). Él sostiene:

Desde este punto de vista, podemos valorar mejor el significado del Theophrastus redivivus: a una tradición teísta y espiritualista, que parecía patrimonio intangible de la civilización europea o, más bien, el patrimonio común de toda la civilización mediterránea desde sus más antiguos orígenes, el autor no sólo contrapone una visión ateísta y materialista, sino que la concibe como característica constante de toda la más auténtica tradición filosófica. No más la santificación de Platón o de Epicuro, no más pia philosophia, sino defensa del ateísmo de todos los filósofos cuya "impiedad" aquí queda demostrada y celebrada como el mejor fruto del ejercicio de la razón humana. El autor quiere, de este modo, retomar una obra de Teofrastro, su "historia eorum quae de deo dicuntur", irremediablemente perdida como tantas otras de la antigüedad... la "restauración" de un patrimonio antiguo no responde sólo a una curiosidad erudita sino a la exigencia de restituir los instrumentos para una batalla cultural que los tiempos exigen (Gregory, 1979, p. 12).

Canziani y Paganini nos advierten que, para determinar el origen y el ámbito del cual proviene el Theophrastus, se deben considerar dos serias dificultades: por un lado, las que, de hecho, hacen imposible la identificación del autor ya que ni el texto ni la historia de la tradición nos lo aclaran; por el otro, que el núcleo más conspicuo y autorizado de los testimonios manuscritos pertenece al ambiente cultural vienés, lo cual no es coincidente con la matriz francesa de la obra a la cual se han referido las más recientes orientaciones historiográficas (Canziani/Paganini, 1981, vol. I, p. LIII). 
Las dificultades señaladas, siguen comentando Canziani y Paganini, no son suficientes para invalidar las hipótesis sugeridas por los estudiosos: estas últimas continúan siendo corroboradas por elementos que pueden extraerse a partir de un análisis interno del mismo texto. La hipótesis que sostiene que París ha sido el ámbito en el cual ha surgido el Theophrastus parece ser la más plausible. Señalan Canziani y Paganini que, a favor del origen francés de la obra, hay que señalar, ante todo, la sensible afinidad entre el clima cultural que se refleja en la obra y las bien conocidas inclinaciones humanistas y eruditas propias de los círculos libertinos más allá de los Alpes. Marcas más determinadas surgen de algunas referencias contenidas en el texto: personajes políticos y autores del siglo XVII mencionados en el anónimo y ediciones adoptadas por las citaciones que parecen remitir directamente al ámbito francés.

La obra se compone de seis tratados. Este ordenamiento, nos dice el mismo autor del escrito, sigue el orden que el viejo Teofrastro (371 a.C - 287 a.C.), sucesor de Aristóteles en la dirección del Liceo, estableció en su escrito. El primer tratado considerará la cuestión de los dioses; el segundo, la del mundo; el tercero, la de la religión; el cuarto, la del alma y de los infiernos; el quinto, la de la muerte que no se debe temer y, finalmente, el sexto, la de la vida según la naturaleza (Theophrastus redivivus, Proemium 7, p. 8.).

El punto focal de toda la polémica del Theophrastus, como acertadamente lo señala Gregory, es el complejo de las creencias religiosas y, ante todo, el de la existencia de Dios (Gregory, 1979, p. 20). Precisamente, como podrá advertirse más adelante, a esta cuestión se aboca el primer tratado de la obra, la cual se abre con la distinción entre legislatores y sapientes. ${ }^{1}$

\section{Propósito del escrito}

El Theophrastus redivivus se propone mostrar que la verdadera filosofía griega, de impronta esencialmente ateísta, ha sido adulterada por el cristianismo el cual pretendió mostrar una perfecta armonía entre la razón griega y la fe. En esta tarea de subvertir la auténtica filosofía griega, los cristianos apelaron a la destrucción de no pocas obras de los pensadores hele-

1 Resulta curioso que el primero de esos sapientes fuera Platón el cual no es considerado sabio por afirmar la existencia de Dios, sino todo lo contrario. Platón, para nuestro autor anónimo, fue ateo. Platón se muestra como sabio para ocultar su condición de ateo; de este modo, evita provocar la ira del pueblo y de los gobernantes. 
nos. Refiere nuestro autor que una parte de libros de los antiguos, referida a la religión, fue destruida, de modo deliberado, por Gregorio VII el cual hizo quemar obras en lengua latina porque las creía licenciosas o peligrosas para el pueblo cristiano. Del mismo modo procedió Gregorio Nacianceno con otros libros de autores griegos. Por estos u otros avatares, también fue extraviada la obra de Teofrastro que narraba la historia de los dioses. $^{2}$

La constatación de esta realidad debía conducir a escribir algo semejante a esos libros. Nuestro autor anónimo, entonces, se propuso revivir a Teofrastro, cuya obra perdida en seis libros, según Laercio, ofrecía al lector una historia de los dioses (Theophrastus redivivus, Proemium, 3).

Nuestro autor se presenta como cristiano; no se olvida, además, de su formación personal y de la educación recibida por parte de sus superiores. Refiere al respecto:

Tampoco me olvido de mi formación personal o tengo una mala predisposición de manera tal que quisiera olvidarme por completo de la educación de la que he dado pruebas, ordenada por los superiores, transmitida por los antepasados y grabada e inculcada por mis maestros en mi alma desde los comienzos (Theophrastus redivivus, Proemium, 4-5).

Sin embargo, como podremos advertir a medida que va exponiendo su pensamiento, su intención es la de producir una verdadera revolución cultural al sostener que la filosofía, en cuanto obra de la razón humana, es atea y que, por lo tanto, la operación llevada por el cristianismo de cristianizar el

2 “Enim, ut scribit Cardanus [lib. $2^{\circ}$ de sap.], librorum ut hominum conditio est; quidam enim morbis sponte pereunt, quidam invidorum aut inimicorum fraude, quidam in communi calamitate, sic et librorum, alii ob incuriam, quod inutiles sint et inculti, negliguntur; alii quod quamquam elaborati essent, melioribus tamen in eo genere succedentibus, grati esse desierunt, velut Erasistrati volumina propter Galenum et Trogi historia propter Iustinum; alii in communi calamitate pereunt velut Ciceronis quidam libri, Livii et Sallustii maior pars historiarum, M. Varronis firme tota illa congeries librorum, quamquam parsa consulto quae ad sacrorum vetustorum religionem pertinebat, a Gregorio VII Pontifice Romano deletasit, qui et plurimos alios Romanae linguae scriptores concremavit, quia aut lasciviores, aut christiano nomini infensi essent. Consimili studio Gregorius Nazienzenus Graecos libros extinxit, nihilominus plures etiam reliquerunt, qui aut probarentur, aut voluntati eorum non subiacerent. Ergo hae communes librorum calamitates seu ex mutatione imperii, orbis acd linguae, seu religionis, seu ex incendio (ut Bibliotheca Alexandrina, in quâ ferunt septingenta millia librorum intercedisse et in conflagratione pacis templi Romae) nobis etiam libros et historiam quam de diis scripserat Theophrastus, misere eripuêre” (Proemium, 3). 
pensamiento filosófico griego ha sido una verdadera impostura. Luego de declararse falsamente cristiano, expone su verdadera intención en estos términos:

A partir de la doctrina de los antiguos y de los otros filósofos, afirmaré que Dios no existe y que de la misma manera se debe despreciar el mundo eterno, el alma mortal, los infiernos fabulosos, la religión, el arte, la política, las opiniones de los astutos y la muerte, aunque de aquella doctrina no se debe esperar nada a futuro; por lo tanto, el único bien propio del hombre es esforzarse por una vida placentera y promover un estilo de vida alegre (Theophrastus redivivus, Proemium, 7).

\section{La razón natural y verdadera y la verdad}

Entre la razón natural y verdadera, la ciencia y la verdad existe una conversión perfecta. Para nuestro autor, la razón natural y verdadera es aquella que no se doblega ante autoridad alguna sino solo ante los hechos (Theophrastus redivivus, Proemium, 13). Estos últimos son solo percibidos por los sentidos. Desde este punto de vista, nos dice nuestro autor, Sócrates ha sido el hombre de la razón verdadera por cuanto solo reconoció como fuentes del conocimiento a los sentidos y a la razón (Theophrastus redivivus, Proemium, 13). Sócrates nos enseñó, entonces, que la única ciencia segura es aquella que comienza por un dato aportado por los sentidos y que cualquier conocimiento que pretenda establecerse como tal, al margen del conocimiento sensorial, no puede ser una ciencia verdadera. Refiere el autor en cuestión:

Con la razón verdadera y natural y con los sentidos acordes según la naturaleza, convocaremos de nuevo a los que se preguntan qué puede ser verdadero, qué (puede ser) falso a partir de los errores con los que casi todos están ocupados y abrazaremos la ciencia segura e indudable. En efecto, ninguna ciencia es segura sino la que se percibe a partir de los sentidos; cualquier conocimiento que está alejado de aquellos no es una ciencia verdadera sino una opinión que se modela y se construye de acuerdo con el deseo y el arbitrio de cada uno: pero la ciencia y el conocimiento que tienen su origen en los sentidos siempre es íntegra y con ella están de acuerdo todos y nunca se pone en duda (Theophrastus redivivus, Proemium, 14).

De lo afirmado anteriormente se desprende que toda la doctrina elaborada acerca de los dioses deberá someterse al juicio de la razón natural y verdadera, la única capaz de producir ciencia y verdad. 
Esta razón natural y verdadera, según nuestro autor, ha sufrido un eclipse provocado por el cristianismo. La prueba más palpable de ello es la existencia de la religión. Para él, la presencia de la religión en los pueblos es proporcional a la no operatividad de la razón natural y verdadera (Theophrastus redivivus, Tractatus primus, cap. I, 26).

Pero entonces, ¿cómo se sostiene la existencia de los dioses? No precisamente por la razón, nos dirá nuestro autor, sino por la fe, por la creencia. Pero, ¿qué es creer? Es tener por verdadera una afirmación a partir del relato de otros, por fuera de la constatación de los sentidos y de la razón. Pero ¿de dónde extrajeron la afirmación de la existencia de los dioses los antepasados? Resulta evidente, para nuestro autor anónimo, que solo es posible una afirmación semejante desde una representación. Esta última es una cosa producida y concebida en la mente sin contar con el testimonio de los sentidos. En consecuencia, ninguna representación hace presente en el alma humana una existencia verdadera sino solo una idea producto de la pura imaginación. Leemos en el Theophrastus:

Cualquier cosa que puede ser producida y ser concebida en la mente sin la asistencia de los sentidos no es sino una representación, que no tiene ninguna esencia verdadera o existencia o sustancia: y no puede ser percibida de otra manera sino en cuanto su ser ha sido formado y determinado a partir de aquellas cosas que la mente ha extraído anteriormente de los sentidos. Por ejemplo, cuando un ente de razón, que de ninguna manera existe en la realidad, sino que se forma y se representa por el intelecto solamente, la mente lo imagina tal como sucede con el hircocervo: la mente no puede comprenderlo si no conoció antes qué es un macho cabrío y qué es un ciervo, con los que se conforma un ente de estas características. Por consiguiente, solo son representaciones aquellas cosas que se dicen que son concebidas en la mente si antes no fueron percibidas por los sentidos (Theophrastus redivivus, Tractatus primus, cap. VI, 96).

La representación es, entonces, un puro ente de razón sin correlato alguno en la realidad.

A partir de esta concepción gnoseológica, tanto la metafísica como la religión serán consideradas como meras representaciones, lo que equivale a afirmar, meras invenciones de la mente humana de las cuales no puede esperarse verdad alguna, aunque sí, como veremos más adelante, una real utilidad.

La teología sobrenatural, según su criterio, no es una ciencia sino un conocimiento totalmente falaz. Esta pseudociencia se funda en la revelación, la cual no es sino una idea que la mente concibe en virtud de la fuerza de la 
imaginación: esta idea es acrecentada y confirmada por la credulidad misma, sin participación alguna de la divinidad (Theophrastus redivivus, Tractatus primus, cap. VI, 103-104).

Ahora bien, si los filósofos se han afanado tanto en su búsqueda solo alentada por el testimonio de los sentidos y por la razón natural y verdadera, rechazando siempre todo argumento de autoridad, ¿por qué estos mismos sabios admitieron la existencia de los dioses?

En efecto, según nuestro autor, tantas cosas diversas se han dicho acerca de los dioses que nada seguro puede decirse acerca de ellos. Esto último, lo asegura, nos lo ha dicho el mismísimo Platón (Theophrastus redivivus, Tractatus primus, cap. III, 54). Incluso, afirma el pensador anónimo, San Juan Damasceno ha sostenido que solo comprendemos, respecto de Dios, que no puede ser comprendido. Refiere: "Et Ioannes Damascenus solum hoc eius comprehendi posse dicit, quod comprehendi non potest" (Theophrastus redivivus, Tractatus primus, cap. III, 53).

Nos permitimos, en este punto, una digresión. Se ha sostenido que el pensamiento libertino se ha caracterizado por su erudición. Lorenzo Bianchi, refiriéndose al Theophrastus, sostiene que resulta paradigmático el método expositivo utilizado en el mismo, esto es, una recopilación de citas extraídas de la antigüedad clásica y de las fuentes renacentistas con un uso muchas veces tendencioso, ordenado a cimentar su visión ateísta (Bianchi, 1988, 112). Puede advertirse, de modo bastante evidente, cómo el autor del texto del Theophrastus adultera, deliberadamente, el verdadero pensamiento de Juan Damasceno. En realidad, Juan Damasceno no niega que el hombre pueda conocer la existencia de Dios, solo afirma que el hombre no puede conocer a Dios como es en sí mismo. Refiere el Damasceno:

“A Dios jamás nadie lo ha visto: sólo el Hijo unigénito, que está en el seno del Padre, Él lo ha revelado”. En consecuencia, lo Divino es indecible y excede toda comprensión (...) Sin embargo, Dios no nos ha abandonado en la nesciencia más absoluta, puesto que ha infundido en todos, el conocimiento natural de su existencia (Damasceno, 2013, 1).

Para Damasceno, todo hombre puede estar seguro de la existencia de Dios solo a través del conocimiento natural que tiene de la misma.

Sin embargo, pese a saber que los dioses no tienen existencia alguna, prosigue en su argumentación nuestro autor anónimo, los filósofos no se ocuparon de destruir la creencia en los dioses en virtud de la utilidad que los mismos prestaban a la configuración y consolidación de la ciudad. 


\section{Crítica a la metafísica y a la teología sobrenatural}

La concepción gnoseológica del autor del Theophrastus lo conduce a una crítica radical de la metafísica y la teología sobrenatural. Comienza afirmando que todo conocimiento seguro se obtiene a partir de las cosas mismas y de los sentidos que las testimonian (Theophrastus redivivus, Tractatus primus, cap. VI, 96). Los sentidos son los indicadores más seguros de todo conocimiento y son ellos lo que generan y orientan a la verdadera ciencia. Si bien el conocimiento se produce en el intelecto, son los sentidos los que le suministran a este último la materia prima. Pero es menester distinguir el conocimiento genuino de aquello que es una representación. Esta última, para nuestro autor, es una cosa producida y concebida en la mente sin la asistencia de los sentidos (Theophrastus redivivus, Tractatus primus, cap. VI, 96). De allí que ninguna representación pueda contener en sí misma alguna esencia verdadera o existencia o sustancia. La representación es producida, enteramente, por la imaginación.

Por lo tanto, desde esta óptica, los objetos que considera tanto la teología sobrenatural como la metafísica son representaciones. El verdadero co-nocimiento se funda en la siguiente tríada: razón, sentidos y observación (Theophrastus redivivus, Tractatus primus, cap. VI, 109-110). El Theophrastus exhorta al lector del mismo modo en que lo hará más adelante Francis Bacon a remover de la mente toda doctrina alejada del testimonio de los sentidos. Por ello, para nuestro autor, la historia no puede tener rango de ciencia, por lo cual está absolutamente devaluada. Refiere el autor anónimo:

Luego, la ciencia no puede ser la ciencia de las cosas pasadas y ausentes; pero, puesto que por nuestro sentido hemos conocido que los sentidos de los otros también son verdaderos y están al servicio de los nuestros, de manera semejante ellos mismos configuran también la ciencia para nosotros. En efecto, si una cierta doctrina inútil y alejada de los sentidos en ocasiones se aloja en nuestras mentes, así como a menudo le sucede a un hombre que sueña, inmediatamente debe ser removida (Theophrastus redivivus, Tractatus primus, cap. VI, 109-110). ${ }^{3}$

3 Ergo scientia rerum praeteritarum et absentium non esset scientia; sed quia sensu nostro experti sumus aliorum sensus etiam veros esse et nostris subservire, consimiliter faciunt et ipsi nobis scientiam. Igitur si forte opinio inania quaedam et a sensibus remota, veluti somnianti saepe evenit, mentibus nostris subiicit, haec amovenda prorsus sunt. 
El mundo metafísico es reemplazado, en el Theophrastus, por la naturaleza, naturaleza, esta, que se identifica con el mundo entero que contiene a todas las cosas. Compara la naturaleza con un cuerpo compuesto de miembros individuales. La divinidad solo existiría si calificásemos como divina a la naturaleza. Para nuestro autor, la naturaleza es un todo orgánico que tiene movimiento propio; nada hay por debajo ni por encima de ella. Todas las cosas dependen de ella (Theophrastus redivivus, Tractatus primus, cap. IV, 59). La doctrina creacionista adultera la naturaleza toda vez que la hace depender de un Dios distinto de ella. La naturaleza es un principio sin principio.

Ahora bien, esta naturaleza gobierna las cosas de este mundo mediante una ley invariable: todas las cosas se desarrollan y gobiernan por el destino. Para nuestro autor, el destino es la energía de las cosas ordenadas entre sí por un orden causal. Sin embargo, afirma, hay cosas que están fuera del orden de la naturaleza y que, por lo tanto, se suceden sin propósito ni orden alguno (Theophrastus redivivus, Tractatus primus, cap. V, 60). Eso se denomina fortuna.

El filósofo auténtico, guiado solo por los sentidos y la razón, no tiene en cuenta ningún argumento de autoridad: busca el conocimiento y escapa a toda representación, la cual, como ya lo vimos, es generada por la imaginación. Pero entonces, la afirmación que tiene por verdadera la existencia de los dioses es una pura representación ya que del mundo metafísico ningún hombre puede tener noticia alguna a través de los sentidos. Dios es una representación (Theophrastus redivivus, Tractatus primus, cap. VI, 108-109). La creencia en los dioses es fruto de la imaginación del hombre. Cabría preguntarse si, aun concediendo al autor del Theophrastus que la razón no puede afirmar la existencia de un mundo metafísico, no existiría la posibilidad de que el Dios creador se haya revelado al hombre. ¿Qué valoración le merece la revelación?

La revelación, nos dice, “... es una aparición o una visión de dios llevada a cabo por los hombres ya sea que estén despiertos o estén soñando" (Theophrastus redivivus, Tractatus primus, cap. VI, 103). Dios no puede aparecerse a los hombres cuando están despiertos porque la única manera de percibirlo a través de los sentidos sería teniendo un cuerpo. Pero un ser perfecto no puede adoptar una forma imperfecta. En consecuencia, resulta imposible que Dios se muestre directamente al hombre. Tampoco es posible que se aparezca al hombre en sueños ya que aquello que no puede ser visto por alguien despierto menos lo puede ser por alguien que sueña. La revelación, en síntesis, es una idea de la mente concebida por la fuerza de la imaginación (Theophrastus redivivus, Tractatus primus, cap. VI, 103) y 
acrecentada y confirmada por la credulidad misma, sin participación alguna de ningún Dios. Y remata:

Por consiguiente, es manifiesto que ninguna revelación o visión puede producirse ni por iluminación ni por aparición. A esto se añade que no puede afirmarse con seguridad que alguna revelación sobre dios pueda ser hecha por el mismo dios que se desconoce en el mismo momento en que la revelación ha sido realizada por él mismo, o bien conocían a dios o no tenían ninguna idea de él. No lo conocían objetivamente (Theophrastus redivivus, Tractatus primus, cap. VI, 104). ${ }^{4}$

Nunca se ha dado, para nuestro autor, una revelación. De allí que la fe sea completamente falaz, incapaz de ofrecer conocimiento verdadero alguno: las revelaciones son meras invenciones.

Pero entonces, ¿cómo se explica la existencia, en la vida de los pueblos, de los dioses? Si bien se esfuerza por refutar el argumento del consenso de los hombres respecto de la existencia de Dios, sosteniendo que existieron ciertos pueblos de África y los celtas en España que negaron la existencia de los dioses como, así también, existieron insignes hombres que fueron ateos (Platón, Aristóteles, Sócrates, Protágoras, Diágoras, Critias, Séneca, Cicerón, Epicuro, etc.), sin embargo no puede dejar de reconocer que la afirmación de la existencia de los dioses siempre acompañó a los hombres, aun cuando, en realidad, eran, en su mayoría, ateos. Nuestro autor hace referencia a la existencia de un ateísmo práctico, observando que, si realmente los hombres creyesen, obrarían bien. Se obraría de acuerdo con aquello que se cree, pero, sin embargo, sucede lo contrario. Refiere que: “...en tiempos pasados existieron una cantidad incontable de hombres ateos y aún ahora también existen; de este tipo fueron todos esos que sobresalieron en la filosofía y que superaron a todos los otros en doctrina" (Theophrastus redivivus, Tractatus primus, cap. IV, 55). ${ }^{5}$

El autor del Theophrastus no tiene duda alguna en afirmar que la creencia en relación con los dioses es completamente una invención de los legisladores y de los políticos (Theophrastus redivivus, Tractatus primus, cap. IV,

4 Igitur nullam fieri revelationem nec per illuminationem, nec per apparitionem, seu visionem manifestum est. Adde quod non potest recte affirmari revelationem aliquam de deo fieri a deo ipso, qui ignoratur eo momento quo revelatio facta dicitur. Nam qui primi hanc revelationem sibi factam fuisse dixerunt, aut deum cognoscebant, vel nulla de eo notio illis erat.

5 Quin etiam innumeri homines olim fuerunt, et nunc etiam sunt athei; eiusmodi fuerunt ii omnes qui in philosophia excelluere et caeteros omnes doctrina superavere. 
57). Los legisladores, considerando que las leyes se ordenan a lo útil (a lo que resulte bueno y ventajoso establecer) y no a lo verdadero, consideraron propicia la creación de los dioses para que los hombres obedezcan las leyes. Refiere el pensador anónimo:

Por esto, la autoridad de las leyes beneficia y protege a los dioses inventados adecuadamente, pero prueba de manera incorrecta que ellos verdaderamente existen y se manifiestan. Los dioses, efectivamente, son hijos de las leyes; el cuidado de los hijos está ligado a ellos, que sabemos, sin embargo, que fueron creados y organizados por las leyes; es algo sin sentido hacerlos creadores de todas las cosas (Theophrastus redivivus, Tractatus primus, cap. IV, 57). ${ }^{6}$

Y añade más adelante:

Por otra parte, en primer lugar, la revelación fue imaginada por los legisladores y los príncipes para quienes es completamente útil que esta doctrina sobre los dioses se introduzca en los espíritus de los hombres para mantenerlos unidos en una obligación, como ya lo hemos aceptado en los capítulos precedentes y lo desarrollaremos con mayor profundidad en el tratado de la religión. En consecuencia, nadie podría poner en duda que la fe es una absoluta representación de los legisladores y de los príncipes que se adueña de la razón (Theophrastus redivivus, Tractatus primus, cap. VI, 105). ${ }^{7}$

\section{La utilidad de los dioses en la polis}

Toda verdad, como ya hemos visto, solo puede proceder de la razón natural y verdadera. Esta razón nos enseña que no existe ningún dios y que de la naturaleza todo procede. Nada hay ni antes ni después de la naturaleza, excepto ella misma. Todas las cosas, en consecuencia, dependen de la naturaleza y el mundo, por eso, es eterno. Refiere nuestro autor:

\footnotetext{
6 Itaque legum authoritas recte fictos fovet et tuetur deos, sed male probat eos vere esse et existere. Dii quidem legum filii sunt; ad illos ideo filiorum cura pertinet, quos autem conditos et constitutos a legibus fuisse scimus, vanum est eos rerum omnium conditores facere.

7 Porro revelatio primum conficta fuit a legislatoribus et principibus, quibus admodum utile est hanc de diis opinionem hominum animis insinuari ad continendos illos in officio, ut in praecedentibus iam innuimus et diffusius in tractatu de religione declarabimus. Igitur fidem merum esse legislatorum et principum figmentum nemo rationis compos dubitaverit.
} 
Hemos demostrado en el capítulo anterior que la naturaleza solo depende de sí misma y no es guiada ni regida por nadie sino que lo puede ser por su propio e interno cambio; ella es, pues, el principio del movimiento y de la quietud: aunque sea un principio, ella misma no tiene un principio, por consiguiente, ella es guiada y regida por sí misma y por su propio movimiento y no, por contrapartida, por la providencia que supone una dependencia en la naturaleza que es completamente independiente (Theophrastus redivivus, Tractatus primus, cap. V, 60). ${ }^{8}$

Pero veamos: si bien la existencia de los dioses no es más que una pura fantasía de mentes alejadas de la verdad, no obstante, la misma es de fundamental importancia para la configuración y consolidación de las ciudades. Los sabios de la humanidad siempre supieron que no existió jamás un dios; sin embargo, sabiendo que esta doctrina agradaba a los pueblos y era la razón principal para conducir al vulgo a la obediencia de las leyes, los legisladores introdujeron la doctrina acerca de los dioses (Theophrastus redivivus, Tractatus primus, cap. VI, 111).

Todos los relatos acerca de los dioses tienen una sola finalidad: hacer que los hombres se sientan obligados a obedecer las leyes de la ciudad. "Luego, los dioses no son nada, excepto solo una invención de los legisladores y una creación de los políticos" (Theophrastus redivivus, Tractatus primus, cap. VI, 115). ${ }^{9}$ Los legisladores introdujeron estos falsos relatos, que son fácilmente destruidos por la razón verdadera y natural, a través de diversos medios entre los cuales se cuenta la violencia. Estas falsas creencias se afianzaron mediante la repetición; desde la más tierna infancia los niños fueron sometidos por las madres y nodrizas a escuchar estas fabulosas narraciones, las que se vieron reforzadas, luego, por las prácticas culturales y un relato popular hegemónico.

Ahora bien, si las doctrinas fabulosas sobre los dioses son necesarias para conducir a los hombres al cumplimiento de las leyes y las mismas son muy poco verosímiles, ¿por qué el ateísmo no se universalizó pese a los esfuerzos, en sentido contrario, de los legisladores? La única explicación posible

8 Naturam autem a se ipsa tantume pendere superiore capite declaravimus et a nullo regi atque gubernari, nisi a suo proprio et insito motu potest; illa enim est principium motus et quietis: cum sit principium non habet ipsa principium, ergo a se ipsâ et suo proprio motu regitur atque gubernatur, non autem a providentiâ, quae supponit dependentiam in natura, quae omnino independens est”.

9 Nihil ergo sunt dii, praeter merum legislatorum commentum et politicorum figmentum. 
es la de sostener que existen dos tipos de hombres: aquellos capaces de llegar a ser sabios y aquellos otros destinados a la ignorancia.

Las religiones son un producto humano hábilmente utilizado para fines políticos y, en consecuencia, si son una pura creación histórica, todas están destinadas a perecer, ley a la que toda cosa de esta naturaleza está sometida: nacer y perecer.

El autor del Teofrastro considera la vida política con los ojos del poder y de la cantidad necesaria para garantizar el orden, esto es, el poder indiviso y sin frenos. Su base antropológica totalmente negativa, que convierte al hombre en un ser de puras pasiones, lo conduce a ver en el orden y en las reglas de la conservación del Estado la única finalidad de la política. Afirma Taranto:

Los libertinos, en efecto, leen el desorden como una tendencia general del ser humano no guiado más por la ratio, sino movido y agitado por pasiones sin límites. El amor propio, el interés, el utilitarismo de las acciones humanas, según una línea que, desde Montaigne llega hasta Rochefoucauld, al jansenismo y en ciertos aspectos a Hobbes y que lucha, explícitamente, contra la moral estoica, generan un estado de conflicto permanente que ya no puede ser eliminado, sino simplemente controlado. Y frenar, controlar, conservar es casi la palabra de orden de los libertinos que, al menos en este punto, no manifiestan apreciables diferencias dentro de ellos, unidos en la reconstrucción, echando mano de materiales estoicos, de aquel concepto intelectual y político de populacho que del desorden parece ser el natural portador (Taranto, 1989, 272).

Y refiere el autor del Teofrastro:

Finalmente, a todas estas doctrinas fabulosas sobre los dioses que han sido inventadas claramente para someter a los hombres a una obligación, Platón [ibidem] las acepta expresándose de esta manera: el tema más importante es que tú no pienses nada de modo que cualquiera viva bien o mal teniendo una opinión correcta sobre los dioses. Ciertamente, con esta manera de pensar las doctrinas sobre los dioses son muy útiles, aunque poco verosímiles. Luego, sólo se podría tratar sobre su utilidad; en lo que concierne a la verdad, ni la fe en una religión, ni la autoridad de un legislador pueden convencer a una mente lúcida que hay de verdad. Pero si la agudeza de talento nunca consideró ciertas posibilidades en este tema de tal manera que a una mente dubitativa y poco segura de sí misma la vuelva segura, al menos que recurramos a aquello para reconocer de mejor manera que nosotros ignoramos esta hermosa inven- 
ción, qué es y de qué tipo que confesar que somos y verdaderamente permanecemos estúpidamente (Theophrastus redivivus, Tractatus primus, cap. VI, 113). ${ }^{10}$

El Theophrastus se ocupará de poner de relieve la vinculación intrínseca entre la filosofía antigua y aquella filosofía libre, impía y ateísta que el pensamiento libertino venía proponiendo con extrema cautela y sutiles simulaciones.

Resulta curioso que nuestro autor afirme, a la par de sostener la tesis que sustenta que la naturaleza está regida por la ley de la necesidad, la existencia del libre albedrío. Afirma en este sentido:

Por lo expuesto más arriba puede demostrarse la existencia del libre arbitrio; todos los días experimentamos que (...) actuamos con la fuerza de la sola voluntad, no por el destino, ni por la necesidad ni por la providencia. Pues, si somos dominados por el destino y la providencia ¿de dónde proviene esta libertad que sentimos que existe en nosotros mismos? (Theophrastus redivivus, Tractatus primus, cap. V, 76). ${ }^{11}$

En nuestra misma voluntad, sostiene, encontramos la posibilidad de querer o no querer (Theophrastus redivivus, Tractatus primus, cap. V, 76). Si bien la voluntad del hombre es cambiante e inconstante (Theophrastus redivivus, Tractatus primus, cap. V, 82), ello no es óbice para que el hombre se autodetermine. De allí que el Theophrastus arremeta contra los astrólogos, el destino y la providencia. No solo la necesidad se opone al libre albedrío, sino que también la previsión de Dios (providencia) se identifica con la necesidad; por eso, para nuestro autor, la incompatibilidad entre providencia y libertad es absoluta. (Theophrastus redivivus, Tractatus primus, cap. V, 77).

10 Tandem omnes istas de diis fabulosas opiniones ad homines in officio continendos plane esse confictas idem Plato [ibidem] innuit sic dicens: maxima res est quam tu nullam putas, ut quis de diis recte sentiens bene aut secus vivat. Hac equidem mente de diis opiniones utilissimae sunt, etsi parum verisimiles. De utilitate igitur solum agendum esset; quod ad veritatem attinet, nec religionis fides, nec legislatoris authoritas quidquam de iis certi mente sanis persuadere possunt. Quod si probabilitatem quandam in hac re ingenii sagacitas umquam excogitant, ita ut mentem dubiam et sui ipsius male certam reddat, saltem eo confugiemus ut fateamur potius nos ignorare pulchrum hoc commentum, quid et quale sit, quam esse et vere existere stulte confiteamur.

11 Quod insuper ex libero arbitrio ostendi potest; illud enim plenum, integrum et absolutum in nobis esse quotidie experimur et solius voluntatis potestate nos moveri, non autem fato, necessitate, providentiâve. Nam si fato regeremur ac providentiâ, unde haec libertas quam in nobis ipsis esse sentimus? 
Sin la existencia del libre albedrío no sería posible la constitución de una civitas. En el libre albedrío se encuentra el origen de la vida en común, de la política. Pero, a la vez, esta vida asociada debe regirse, de modo necesario, mediante leyes. Fueron los legisladores los que, promulgando leyes, configuraron la vida de la polis. Pero, ¿cómo lograron que los hombres obedezcan las leyes?

Estos legisladores, caminando por fuera de la razón natural y verdadera, inventaron a los dioses. Los legisladores fueron plenamente conscientes de que la afirmación de la existencia de dioses solo puede mantenerse a través de relatos míticos acerca de ellos (Theophrastus redivivus, Tractatus primus, cap. VI, 113). Platón, en este sentido, fue uno de los primeros. Esta doctrina sobre los dioses servía para que los hombres se sometieran a la obligación estipulada por las leyes. Entonces la religión, para nuestro autor, merece dos consideraciones: desde el punto de vista de la utilidad es plenamente funcional para mantener la obediencia a las leyes; desde el punto de vista de la verdad es totalmente falsa (Theophrastus redivivus, Tractatus primus, cap. VI, 114). La religión, para él, se muestra como una técnica muy eficiente de control político, un instrumento del cual se sirven los legisladores y los poderosos para dirigir al pueblo.

Advierte Lorenzo Bianchi al respecto:

Este tema del gobierno y del orden, típico del debate político del siglo XVII, llega ahora, en el Theophrastus redivivus, a dos soluciones opuestas, una para el pueblo y otra para el sapiente... aquí el indiferentismo religioso alcanza a valorar el rol central que la religión tiene para los pueblos, pero también a diferenciar radicalmente las exigencias culturales y las expectativas propias del pueblo respecto de los sapientes. Sólo estos últimos llegan a la verdad siguiendo la ley natural, y se elevan de los figmenta y de las imposturas en las cuales el pueblo está inmerso para realizar una autónoma y completa libertad (1988, p. 116).

La sociedad, en consecuencia, se configurará de modo jerárquico. Existirán, por un lado, los jefes-legisladores y los sapientes, y por el otro, la masa inculta. Esta separación radical entre dos clases de hombres no es producto de la naturaleza, sino de las ciencias y de las artes, y está sostenida por una violencia de las leyes y de la organización política instituida por los legisladores. Refiere Bianchi: "El autor del Theophrastus redivivus no se priva de una filosofía consolatoria que es tal en tanto rechaza el mundo externo recluyéndose en un aristocrático 'bien vivir’” (1979, p. 883).

Para nuestro autor, la auténtica libertad solo puede ser alcanzada por el sabio. Pero él no puede liberar a un pueblo que ha sido configurado por una 
tradición religiosa que le ha otorgado una segunda naturaleza: consuetudo enim est altera natura (Theophrastus redivivus, Tractatus secundus, cap. III, 148). El sapiente no solo se distingue del pueblo sino, además, del político. Este último se ocupa del buen funcionamiento de la república y, por eso, del control de la masa; por el contrario, el sapiente solo está ocupado de la verdad. Nuestro autor establece, dentro de la comunidad política, dos órdenes claramente diferenciados: “... uno, externo, social, políticamente compacto, válido para el pueblo; y otro, interno, limitado al sapiente y no extensible al público... ámbito de libertad y autonomía que es imposible querer extender al pueblo" (Bianchi, 1988). El pueblo, como refería Vanini, siempre amará ser engañado: "Mundus vult decipi, decipiatur ergo" (Vanini, 2010, Exercitatio VI, 36, p. 384). El esfuerzo del político, a juicio de nuestro autor anónimo, se orienta a mantener siempre el statu quo, sometiendo las fuerzas pasionales de la masa a los dictados de la ley.

Una visión negativa respecto del ser de la mayoría de los hombres conduce a nuestro autor tanto como a otros libertinos, v. g., La Mothe le Vayer, a la exigencia de un Estado absoluto. Solo un Estado absoluto puede someter a una masa dominada, por naturaleza, por pasiones anéticas. La crisis del derecho natural acaecida ya hacia fines del siglo XVI (Battista, 1966) y la antropología negativa del Theophrastus desembocan en un convencionalismo jurídico de base voluntarista, que considera al soberano como lex animata y a las reglas de la Razón de Estado como cánones prudenciales de su acción de gobierno (Taranto, 1989, 272).

El Theophrastus no se propone llevar adelante una revolución en la vida de los hombres que integran la masa. Por el contrario, pretende mantener el statu quo político a la vez que la existencia de una religión ordenada al dominio de los ignorantes. La filosofía verdadera, esto es, el ateísmo, es privativa de los sabios libertinos. Para nuestro autor solo las mentes lúcidas solo son capaces de descubrir que las historias sobre los dioses son falsas (Theophrastus redivivus, Tractatus primus, cap. VI, 113). Pareciera que hay una tendencia no eliminable en los pueblos a creer en fantasías y a no fundarse en la verdad que solo la razón natural puede ofrecer. En realidad, según nuestro autor, la doctrina sobre los dioses agrada a los pueblos (Theophrastus redivivus, Tractatus primus, cap. VI, 111).

La imposibilidad de universalizar el ateísmo no sería para el autor del Theophrastus algo negativo ya que la creencia en los dioses permitiría no solo obedecer las leyes sino, además, mantener la estabilidad política. Reconoce, asimismo, que sin la existencia de la religión toda sociedad se disolvería (Theophrastus redivivus, Tractatus primus, cap. IV, 57), ya que la religión ha sido considerada como el alma, la firme columna de una socie- 
dad, única forma de organización de la república y de las distintas leyes.

Pero, entonces, ¿qué función cumpliría, en una sociedad política, una élite ilustrada a la que le resulta imposible bajar a la caverna y liberar de la ignorancia a sus semejantes?

Consideramos que la función asignada a esta élite es la de conducir la vida de los pueblos: a ella le compete forjar las leyes y configurar la vida de la polis; es ella la que puede formular una ciencia política que sea capaz de enseñar a los hombres que conducen aquellas leyes permanentes que se registran dentro de un ámbito tan inconstante como es el de las acciones humanas.

Esta ciencia política obtendría sus principios mediante la vía inductiva, a través de la observación de aquello que acontece en la vida de los pueblos. Esta observación, procesada por la razón natural, dará lugar a la existencia de principios que permitirán leer y dirigir los acontecimientos políticos. Pese a que el mismo autor del Theophrastus haya señalado la volubilidad de la voluntad humana, no puede dejar de admitir la existencia de ciertas elecciones que se producen, a lo largo de los tiempos, de igual modo. Sin la existencia de constantes en el comportamiento de los hombres no sería posible elaborar una ciencia política en tanto instrumento fundamental de las élites para gobernar a los pueblos.

Tanto la existencia de élites ilustradas como de masas ignorantes no son eliminables en la vida de los pueblos: la vida política depende de esta interacción constante entre ambas clases de hombres y su sanidad depende de la subordinación de la masa a la élite. El esfuerzo de la élite será, precisamente, el de mantener siempre esta relación jerárquica y para ello la religión resulta indispensable. La élite sabe que los dioses son necesarios para que los hombres obedezcan las leyes.

Podemos apreciar, en la concepción de nuestro autor, una visión jerárquica de la política fundada en el conocimiento verdadero. El conocimiento es el fundamento último de la división entre los hombres: solo el conocimiento da derechos para gobernar la polis; la ignorancia solo debe obedecer.

Es una obligación moral de las élites controlar el poder político y, para ello, debe dejar que la religión se propague dentro de la masa. La verdad, es decir, el ateísmo, es para pocos; la falsedad, la religión, es para los muchos que siempre deberán someterse. Para estos pensadores, los ignorantes no son personas que exigen respeto y elevación espiritual, sino una troupe a la que debe conducirse (Pintard, 1983, p. 563).

El prestigioso filósofo de la política, Augusto Del Noce, refiere: 
Humanidad inmodificable, por lo tanto, pérdida de la realidad moral de los otros: no son personas que deban respetarse sino una grey a la que ha de acarrearse... Por eso, la desacralización libertina concluye, en el ámbito de la política, en la apología del absolutismo llevado a sus consecuencias extremas a causa de la desaparición del derecho natural y de la ley divina (Del Noce, 1965, p. 447).

La crítica ateísta del autor anónimo del Teofrasto ha completado la obra de desacralización iniciada con la investigación de los renacentistas de las causas naturales de los milagros. Para nuestro autor, la religión encuentra su origen en la naturaleza humana, en la voluntad política, en la ignorancia del vulgo, en el juego de intereses y pasiones que está en el fondo de toda vida asociada.

Sin embargo, dado que la religión se inserta en las estructuras profundas de la ciudad terrena, el filósofo no deberá intentar modificar un estado de cosas que la costumbre ha transformado en natural; su obra de desacralización debe quedar circunscripta al círculo de los sapientes que, conscientes de la verdadera naturaleza de la religión, saben que la misma resulta esencial y necesaria para el vulgo.

A modo de síntesis de lo que venimos afirmando, refiere Gregory:

La crítica libertina en la cual siempre subyace la oposición entre "público" y "privado", entre vulgus y sapientes se conjuga con un aristocrático conservadurismo: resulta inútil y dañoso intentar difundir la razón allí donde triunfan las pasiones irracionales; la vida pública es regida por la vulgi opinio y esta confiere a la religio su valor de lex idónea para regir un determinado orden político (...) el pensamiento libertino (...) se repliega sobre sí mismo afirmándose como discurso privado por cuanto sólo es capaz de garantizar aquella libertad interior que es la condición de una vida vivida de acuerdo a la razón (Gregory, 1979, pp. 186-187).

Para nuestro autor anónimo, en consecuencia, resultará imposible que se cristalice su anhelo de una "república de los ateos": esta debe ser rechazada de plano por cuanto toda organización política encuentra su fundamento necesario en la mitología religiosa.

\section{Conclusiones}

Hacia fines del siglo XVI, en Francia, se produce una profunda crisis política que conduce a perder de vista los principios de la metafísica cristiana, siendo reemplazados por la doctrina maquiavélica. Giulio Cesare Vanini, 
en su escrito Amphitheatrum del año 1615, señala que durante este tiempo se difunden la herejía y el ateísmo, y añade que incluso aquellos que se autodenominan cristiano-católicos no desdeñan, en la práctica, definirse como políticos de cuño maquiavélico, desconociendo que la divina Providencia ejerce el gobierno del mundo y poniendo en su lugar el gobierno puramente humano (Vanini, 2010, XVI, XIII).

Esta profunda crisis de la conciencia europea se puede apreciar durante toda la primera mitad del siglo XVII en la denominada literatura libertina. Dentro de este movimiento se inserta la obra del Theophrastus redivivus que hemos considerado a lo largo de nuestro escrito.

Esta obra tiene, como propósito principal, mostrar la adulteración que el cristianismo ha producido en la filosofía griega, la cual es, para el autor del Theophrastus, esencialmente, atea. De este modo, la razón natural y verdadera fundada solo en la percepción sensorial del mundo daría lugar a una visión naturalista que desplazaría, de modo definitivo, a la visión metafísico-cristiana.

Esta posición antimetafísica y anticristiana se conjugan, en el Theophrastus, con una antropología decididamente negativa. Sin asumir el dogma del pecado original, nuestro autor anónimo sostiene que la mayoría de los hombres no son capaces de alcanzar la verdad, esto es, el naturalismo ateo propio de una razón natural y verdadera. La división antropológica entre el vulgo y los sapientes se traduce, a nivel político, en una organización necesitada de la religión. La religión, que ha sido inventada por aquellos que han configurado las ciudades mediante las leyes (los legisladores), domestica al vulgo evitando revueltas políticas que pongan en peligro la estabilidad tan necesaria para aquellos que cultivan, de modo solitario, la búsqueda de la verdad.

El ideal revolucionario, a nivel de la polis, se encuentra totalmente alejado de la visión de este autor libertino. La razón natural y verdadera no sería útil, al igual que la religión, para organizar una sociedad que exige, fundamentalmente, estabilidad. En este sentido, la misión principal de la élite ilustrada, respecto de la esfera de la política, es la de su control mediante un ordenamiento fundado en la religión. El autor anónimo, al igual que otros libertinos, privilegia el statu quo de la polis en lugar del cambio.

\section{多}

\section{Bibliografía}

Battista, A. M. (1966). Alle origini del pensiero politico libertino. Montaigne Charron. Milano: Giuffrè Editore. 
BiAnCHI, L. (1979). “Libertinismo e ateismo nel Seicento”. En Studi Storici, 20, (4), 881-886.

(1988). Tradizione Libertina e Critica Storica. De Naudé a Bayle. Milano: Franco Angeli.

Busson, H., (1948). La religion des classiques (1660-1685). Paris.

Canziani, G. y Paganini, G. (1981). Theophrastus redivivus. Edizione prima e critica. Firenze: La Nuova Italia.

Damasceno, G. (2013). Esposizione della fede. De fiede orthodoxa. Testo critico B. Kotter. Bologna: Edizioni Studio Domenicano.

Del Noce, A. (1965). Riforma cattolica e filosofia moderna. Volume I: Cartesio. Bologna: Il Mulino.

GARIN, E. (1970). Dal Rinascimento all'Illuminismo. Studi e ricerche. Pisa: NistriLischi.

GrEgory, T. (1979). Theophrastus redivivus. Erudizione e ateismo nel Seicento. Napoli: Morano Editore.

PinTARD, R. (1983). Le libertinaje érudite dans la première moité du XVII ${ }^{e}$ siècle. Genève-Paris: Slatkine.

SpINK, J. S. (1937). La diffusion des idées matérialistes et antireligieuses au debut du XVII ${ }^{\mathrm{e}}$ siècle: le “Theophrastus redivivus”. Revue d'histoire littéraire de la France, 248-255.

TARANTO, D. (1989). Libertinismo e assolutismo, un rapporto critico? Pensiero político, 264-277.

VAnini, G. C. (2010). Amphitheatrum aeternae providentiae. En Giulio Cesare Vanini. Tutte le opere. Milano: Bompiani.

WADE, I. O. (1938). Clandestine organization and diffusion of philosophic ideas in France from 1700 to 1750 . Princeton University Press. Princeton, 222-228.

Fecha de recepción: 03/10/2016

Fecha de aceptación: 21/12/2016 